\title{
Justicia restaurativa en violencia intrafamiliar y de género
}

\author{
Isabel Ximena González Ramírez*
}

\begin{abstract}
RESUMEN
Este trabajo plantea un análisis de la evaluación de la aplicación de la mediación penal como mecanismo de resolución colaborativa en conflicto de violencia dentro de la familia y pareja, desde una perspectiva criminológica, en la búsqueda de soluciones integrales a las personas involucradas en estas vivencias, explorando los límites y posibilidades que puede proporcionar a las partes y a la comunidad este mecanismo propio de la Justicia Restaurativa, permitiéndoles acceder a actos reparatorios para su dignidad y acuerdos que tengan sustentabilidad en el tiempo. Comparando el proceso y consecuencias de esta forma colaborativa de abordar este tipo de conflictos con la oferta que plantea hoy el sistema penal público en Chile.
\end{abstract}

Violencia intrafamiliar - justicia restaurativa - mediación penal

\section{Restorative justice in domestic and gender abuse}

\begin{abstract}
This paper presents an analysis of the implementation of criminal mediation as a collaborative mechanism for conflict resolution within the family and relationships, from a criminological perspective. It advocates comprehensive solutions for the people involved in such experiences, exploring the limits and possibilities that these mechanisms of Restorative Justice may supply parties and the community itself. They could additionally allow access to reparatory measures and agreements that are sustainable over time. This collaborative process to address such conflicts and its consequences are compared with the current arrangements of Chilean criminal justice.
\end{abstract}

Domestic abuse - restorative justice - criminal mediation

* Abogada, Magíster en Derecho, Profesora de Derecho Penal y de Mediación en la Facultad de Derecho de la Universidad Central de Chile, Santiago. Correo electrónico: igonzalezr@ucentral.cl

Artículo recibido el 30 de agosto de 2013 y aceptado para su publicación por el Comité Editorial el 28 de octubre de 2013. 


\section{INTRODUCCIÓN}

$\mathrm{E}$ n la última década, las políticas públicas en materia de justicia han impulsado numerosas reformas y modificaciones legislativas, tanto sustantivas como procedimentales, enfocadas en modificar tanto el Derecho como la forma de ejercerlo; diversificando las vías de solución de conflictos, introduciendo en los procedimientos mecanismos autocompositivos que generan menores costos en el ámbito emocional, económico, de tiempo, mantención de relaciones posteriores al conflicto y una sensación final de solución integral a las necesidades de justicia de las partes; todas modificaciones que tienen por objeto lograr una transformación cultural en el país transitando desde procesos de solución de conflictos confrontacionales, a aquellos que se sustentan en dinámicas de colaboración, diálogo y respeto mutuo, que junto con reconocer la dignidad a las personas, contribuyen a fortalecer el acceso a la justicia de los ciudadanos/as ${ }^{1}$.

En este marco, el presente artículo tiene por objeto analizar cómo la mediación ha emergido como un sistema de solución colaborativa capaz de resolver los conflictos de violencia de familiares y de género de manera más adecuada que la formal administración de justicia, ello en virtud de la naturaleza sistémica de sus controversias y el tipo de relaciones que están en juego, no obviando algunas importantes restricciones que deben ser consideradas en su aplicación.

Se ha puesto tal énfasis en la inserción de la mediación como política pública, en materia de familia, que incluso debió efectuarse una modificación legislativa a la Reforma a la Justicia de Familia de la Ley N 19.968 de 2.004 que crea los Juzgados de Familia, así como su posterior modificación en la Ley $\mathrm{N}^{\circ} 20.086^{2}$, en que se elimina su carácter de instancia voluntaria y transformarse en un paso previo y obligatorio al inicio de una acción judicial en temas de cuidado personal, alimentos y régimen comunicacional. ${ }^{3}$

El conflicto tratado en este artículo aborda uno de los aspectos relacionales más complejos de nuestra humanidad, la vinculación tanto íntima como social entre hombres y mujeres al interior del grupo familiar. Cuyos aspectos íntimos son considerados a veces irrelevantes para el Derecho, evitando tratar importantes aspectos parentofiliales.

En consecuencia con lo anterior, y por factores culturales, económicos y de desarrollo de la sociedad, donde la figura de la mujer tiene una creciente inclusión en la economía y las exigencias de la vida moderna, se ven afectadas frecuentemente la relación de pareja y de familia, visibilizándose dinámicas de agresividad y violencia al interior de esta,

${ }^{1}$ Bates, L. Ministro de Justicia que debió implementar la incorporación de la mediación a la normativa jurídica en familia. Discurso de inauguración en Congreso Iberoamericano de Buenas Prácticas en Acceso a la Justicia, editado por Ministerio de Justicia, Santiago de Chile, 2006, pp. 1 y 2.

${ }^{2}$ Ley $\mathrm{N}^{\mathrm{o}} 19.947$ de Matrimonio Civil, 2004, contempla por $1^{\circ}$ vez la mediación como forma de resolución de conflictos familiares, luego la Ley $\mathrm{N}^{\circ} 19.968$ que crea los Juzgados de Familia y la Ley $\mathrm{N}^{\circ} 20.086$ publicada en el Diario Oficial el 15 de septiembre de 2008, que la modifica. Entre otros aspectos, estableciendo un sistema de implementación gradual en el país de la mediación previa y obligatoria, encontrándose plenamente vigente a partir del 15 de diciembre de 2009 en todo el territorio nacional.

${ }^{3}$ Castillo, A., Mediación Familiar y Género. Monografía de Magíster en Derecho, Cultura Constitucional y Derechos Codificados. Santiago de Chile, 2010, p. 2. 
afectando a sus integrantes, especialmente a los que son más vulnerables y dependientes, como son los/as niños/as y las mujeres.

Sin embargo, la situación antes descrita produce un desequilibrio entre géneros, lo que atañe directamente al Derecho y exige de este soluciones oportunas y efectivas. A pesar de ello, actualmente nos encontramos frente a un marco legislativo y procedimental complejo, para quien tiene a cargo resolver este tipo de conflictos. El que restringe la procedencia de la mediación familiar y penal, en materia de violencia intrafamiliar, sin perjuicio de que en la práctica esta opera en la sombra, fuera del marco de la ley y sin una normativa que resguarde de manera eficiente los importantes bienes jurídicos en riesgo, por la urgente necesidad de resolver de una forma no punitiva estos conflictos ${ }^{4}$.

En este contexto, este trabajo aporta una reflexión respecto de la pertinencia de abordar situaciones de VIF, especialmente referidas a la violencia de pareja, con la mediación u otro mecanismo restaurativo, que permitan integrar soluciones adecuadas al actual momento histórico-social que cruza la familia y la mujer en Chile, vinculando los efectos que produce la judicialización en este tipo de conflictos, tanto en las partes como en la comunidad, desde una visión propia de la criminología.

La opción de legislar a favor de incorporar la mediación en este especial conflicto, busca propiciar mayor responsabilidad de los afectados en la solución de sus propios conflictos por medio de la práctica del diálogo, favoreciendo la convivencia del grupo familiar, más allá de la ruptura de la pareja. Sin duda, un incentivo para adoptar la mediación es la capacidad de descongestionar la labor judicial, pero este es el aporte de menor importancia, considerando que los mecanismos colaborativos mejoran la calidad de las soluciones que ofrece la justicia por medio de la participación de sus protagonistas, lo que según estudios sobre la materia, genera importantes niveles de satisfacción de los usuarios, además de un mayor compromiso y sustentabilidad en el cumplimiento de las obligaciones acordadas 5 . Asimismo, estos mecanismos ofrecen mayores niveles de bienestar social por el fortalecimiento del acceso a la justicia ${ }^{6}$.

Lo anterior es aún más relevante en materia de familia, por la fragilidad e intimidad de las relaciones entre sus integrantes, que se ven expuestas y vulneradas mediante un proceso judicial. Para este tipo de controversias, la mediación como manifestación de la Justicia Restaurativa ofrece un espacio confidencial y especializado para acoger tanto desde lo emocional y lo concreto, la multiplicidad de conflictos que pueden presentarse entre sus subsistemas parentofilial, conyugal, fraternal, intergeneracional ${ }^{7}$.

\footnotetext{
${ }^{4}$ Castillo, A., Mediación Familiar y Género. Monografía de Magíster en Derecho, Cultura Constitucional y Derechos Codificados. Santiago de Chile, 2010, pp. 3 y 5.

${ }^{5}$ Universidad de Concepción, Facultad de Ciencias Económicas y Administrativas. Estudio (FACEA), "Calidad del Servicio de Mediación Licitado por el Ministerio de Justicia”, Ministerio de Justicia, 2006. En: http://www.mediacionchile.cl/MinJusPubl/Sitio/pub_estadisticas.aspx. Última visita 17 de febrero de 2010.

${ }^{6}$ Peña, C., "Los sistemas alternos de resolución de conflictos como alternativa de política pública en el sector judicial", en Revista de Estudios Sociales de la Corporación de Promoción Universitaria (CPU), No 88, año 1996, p. 91.

${ }^{7}$ Vargas, M., "Mediación Obligatoria. Algunas razones para justificar su incorporación”, en Revista de Derecho (Valdivia), V. XXI, No 2, diciembre 2008, pp. 184 y ss.
} 
Frente al desarrollo progresivo de una tecnología de la coacción, propia de la sociedad moderna, Fourier desarrolla por primera vez una tecnología de la armonía y concordia, desplazando la civilización del control por una organización sin violencia, especialmente del Estado, descartando toda forma de coacción, económica, política y familiar, la que encuentra eco en el pensamiento de Marx, en las doctrinas anarquistas, pensamientos socialistas de Ferri y otros positivistas, opositores al liberalismo de Carrara, abriendo camino al abolicionismo ${ }^{8}$. Quedando instalada la idea del carácter represor del Estado cualquiera sea su modelo, enfrentando a la expansión punitiva una acción cooperativa mucho más activa ${ }^{9}$. Dejando atrás una larga historia de violencia en manos del Estado y todas las consecuencias que esto conlleva, lo que ha constituido el aporte más relevante para la política criminal.

\section{El conflicto En la Justicia Restaurativa}

El conflicto es propio de la naturaleza humana y tenemos que saber convivir con él, es impensable una sociedad sin conflictos, ya que este representa los intereses, el cambio y la evolución necesarios para la especie humana. Pero las fuentes de conflictos no se convierten automáticamente en causas de él, se requieren condiciones de contexto para que esto ocurra ${ }^{10}$.

La intervención del Estado en los conflictos se realiza mediante diferentes políticas con fines preventivos, disuasivos y reactivos. Todos ellos se reflejan en la opción de someter al proceso judicial los conflictos propios del VIF y género, debiera considerar que las relaciones continuarán existiendo entre los miembros de la familia, más allá del problema concreto que es objeto del fallo, situándose las partes en una lógica de vencedores y vencidos, que en nada facilita el restablecimiento de relaciones familiares y el cumplimiento de obligaciones que deben asumir de manera impuesta, deteriorándose más los vínculos afectivos entre los miembros de la familia. Lo que no significa que el Estado deba desentenderse de este grave conflicto, al contrario, debe fortalecer y coordinar las acciones sociales para prevenirlo ${ }^{11}$.

Es así como Bergalli ${ }^{12}$ se pregunta: ¿cómo se puede aceptar la pretensión de un sistema jurídico de responder con los mismos instrumentos y los mismos procedimientos a conflictos de tan vasta heterogeneidad?

Asimismo, Baratta ${ }^{13}$ dice que el sistema penal no es apto para proporcionar las defensas más eficaces de los derechos de las personas, por el hecho de que su intervención

\footnotetext{
${ }^{8}$ Binder, A., Análisis Político Criminal, Editorial Astrea, Buenos Aires, 2011, pp. 126-127.

${ }^{9}$ Dorado Montero, P., Valor social de leyes y autoridades, Barcelona, p. 198.

${ }^{10}$ Binder, A., Análisis Político Criminal, op. cit., p. 151.

${ }^{11}$ Binder, A., Análisis Político Criminal, op. cit., pp. 170-171.

12 Bergalli, R., Sistema penal y problema social, Editorial Tirant lo Blanch, Valencia, 2003, pp. 34 y ss.

${ }^{13}$ Baratta, A., "Notas para una teoría de la liberación”, en Revista Poder y Control, Editorial PPU. N 1 , Barcelona, 1987, pp. 107-119.
} 
está estructuralmente limitada a la formulación de respuestas sintomáticas a los delitos, cuando estos se manifiestan dentro del sistema social.

Por otra parte, García-Pablos de Molina afirma ${ }^{14}$ que la criminalidad es fomentada por el control social y el sistema penal en unión con la sociedad, los que producen el etiquetamiento del delincuente. Esta teoría sugiere que la aplicación de una pena ni previene ni corrige, todo lo contrario, corrompe y estimula futuros actos desviados mediante la aplicación de una etiqueta al infractor, por lo que debiera intentarse buscar alternativas a la pena y a los centros de internación.

Desde la perspectiva de la aplicación del Derecho Penal, mediante un procedimiento que debe necesariamente ser selectivo, va a dejar conflictos criminales sin resolver y los resueltos no siempre lo son de una forma satisfactoria para los ciudadanos, especialmente por la falta de participación colaborativa de las partes en su proceso de resolución, no logrando cumplir de manera integral con las expectativas de justicia de las personas. Es razonable entonces sostener que el delito es visto como violación al Estado, siendo el objetivo final del sistema penal aplicar una pena para castigar o prevenir el delito, adquiriendo el conflicto un carácter interpersonal entre el Estado y el agresor, sustituyéndose el daño ocasionado por el agresor por el perjuicio producido por el Estado a este. Apareciendo la comunidad representada por el Estado y la acción penal orientada desde él hacia el agresor, siendo la víctima ignorada.

Sin perjuicio de lo anterior, existen autores como Zaffaroni que tienen una visión más integral, aborda el delito desde paradigmas más cercanos al sistema restaurativo, observándolo como un conflicto. Sosteniendo que el modelo punitivo ni siquiera resuelve los conflictos más graves, como el homicidio, sino que "Se limita a imponer una pena, sin tener en cuenta las necesidades de la víctima. ¿No será preferible, por ejemplo, que el culpable trabaje y pague a la familia de la víctima?" 15 , "Le da lo mismo a la víctima y a su familia, la gravedad de la pena que se impuso al culpable" ${ }^{16}$. El conflicto queda colgado años hasta que se disuelve, no se resuelve.

Asimismo Bustos aborda el delito en forma muy acertada, concluyendo que una adecuada política criminal debiera concebirlo como un conflicto social ${ }^{17}$.

Por otra parte, Christie sospecha que la criminología, de alguna manera, ha profundizado un proceso en el que los conflictos le han sido arrebatados a las personas directamente involucradas, de modo que o han desaparecido o se han transformado en pertenencia de otras personas, llegando a resultados deplorables. Los conflictos para tener resultados útiles deben ser usados por quienes originalmente se vieron envuelto en ellos, no solo abandonados a su suerte ${ }^{18}$. "En esta situación la víctima es el gran perdedor. No

\footnotetext{
${ }^{14}$ García-Pablos de Molina, A., Manual de Criminología. Introducción y teorías de la criminalidad, Editorial Espasa, Madrid, 1988, pp. 604-640.

15 Zaffaroni, R., Manual de Derecho Penal, Parte General, op. cit., p. 36.

${ }^{16}$ Zaffaroni, R., Manual de Derecho Penal, Parte General, op. cit., p. 37.

${ }^{17}$ Bustos, J.; Hormazábal, H., Nuevo sistema de Derecho Penal, op. cit., pp. 25-27.

${ }^{18}$ Christie, N., "Los conflictos como pertenencia”, traducción de Bovino, Alberto y Guariglia, Fabricio, publicado originalmente con el título "Conflicts as property", The British Journal of Criminology, vol. 17 $\mathrm{N}^{\circ} 1,1977$, p. 159 .
} 
solo ha sido lastimada, despojada materialmente y el Estado toma su compensación, sino que además ha perdido la participación en su propio caso" ${ }^{19}$.

Para Eiras, "El delito para el sistema tradicional es entendido como una infracción a la norma, que es expresión del poder soberano. En cambio desde la mirada de la justicia restaurativa, el delito es un conflicto social, una incompatibilidad de conductas, percepciones, objetivos y afectos entre individuos o grupos sociales" ${ }^{20}$.

En el sistema retributivo la postura de Kant es el pilar fundamental, quien concibió la retribución como un principio jurídico: "El castigo judicial no puede nunca ser usado como mero medio para promover otro bien, ya sea en favor del criminal mismo o de la sociedad civil, sino que debe imponérsele bajo el sustento de que se ha cometido un crimen" 21 .

Es así como se puede señalar, según afirma Eiras $^{22}$, que la justicia retributiva tiene como objetivo probar delitos, establecer culpas y aplicar el castigo al infractor en equivalencia al bien jurídico afectado. Encontrando el control del procedimiento a cargo de los poderes del Estado, quienes tutelan los derechos e imponen la pena, con una orientación de la mirada enfocada al pasado, a los hechos que afectan a la sociedad.

Desde una perspectiva criminológica, Braithwaite, mediante su teoría de la vergüenza reintegradora ${ }^{23}$, ha proporcionado un fundamento empírico para los modelos de justicia restaurativa, más efectivos en el control de la criminalidad que la justicia retributiva, evitando a los ofensores la estigmatización, que les impide vivir como ciudadanos responsables en la comunidad. La vergüenza causada por la reprobación de los delitos por quien tiene lazos de cuidado con el ofensor, mantiene durante el acto de reprobación comunitaria un permanente vínculo de respeto con el infractor, para evitar la estigmatización y prevenir delitos. Posición que ha sido criticada por la teoría del Labelling approach, como criminógena. Sin embargo, Langon Cuñarro sostiene que la teoría de la vergüenza reintegradora "es la reprobación social expresada dentro de un continuo de respeto al ofensor como persona, como en la vieja máxima cristiana: se odia al pecado pero no al pecador. En este caso se trata de reprobar claramente el acto criminal, pero no al autor" 24 .

Desde otro ángulo, Jaccoud ${ }^{25}$ sostiene que la Justicia Restaurativa representa el respeto experimentado y recíprocamente asegurado de la dignidad humana en cualquier

${ }^{19}$ Christie, N., Los conflictos como pertenencia, op. cit., p. 170.

${ }^{20}$ Eiras. N., Ulf C., Mediación Penal, de la Práctica a la Teoría, $1^{\text {a }}$ edición, Editorial Histórica, Buenos Aires, 2004, pp. 36 y ss.

${ }^{21}$ Martin, J., The English Legal System, 4a edición, Editorial Hodder Arnold, Londres, 2005, p. 174.

${ }^{22}$ Eiras, N., Ulf C., Mediación Penal, de la Práctica a la Teoría, $1^{a}$ edición, Editorial Histórica, Buenos Aires, 2004, pp. 36 y ss.

${ }^{23}$ Braithwaite, J., Crime, Shame and Reintegration, Cambridge, Cambridge University Press, 1989, p. 13, Estados Unidos, 2003.

${ }^{24}$ Langon Cuñarro, M., "La teoría de la vergüenza reintegrativa de John Braithwaite", en Revista de la Facultad de Derecho. Universidad de la República, No 18, Montevideo, Uruguay, 2000, pp. 63-67.

25 Jaccoud, M., Ponencia sobre Justicia Restaurativa, en Conclusiones Foro Iberoamericano de Acceso a la Justicia, 2005, editado por el Ministerio de Justicia y PNUD, 2006, pp. 109 y ss. 
circunstancia y frente a cualquier riesgo al que nos exponga su defensa. Se basa en la convicción de que el conflicto tiene tres caras y una de ellas es la sociedad, que debe responsabilizarse en el proceso de justicia, el que no solo pertenece a las partes o al Estado como ente regulador, sino que también pertenece a la comunidad toda, la que debe asumir responsabilidades en relación con los factores económicos, sociales y morales que contribuyen al conflicto.

De esta manera, la Justicia Restaurativa no privatiza ni estatiza el conflicto, y tampoco lo entrega solo a la comunidad, sino que sitúa a estos actores (Poder Ejecutivo, Poder Judicial, comunidad, partes, víctima y victimario) en un equilibrio de poderes y obligaciones respecto del conflicto (identificado por una discrepancia, trasgresión, falta o delito), sus orígenes y consecuencias, formando una red colaborativa. Se puede afirmar que la esencia del enfoque restaurativo entiende que las partes del conflicto se ven perjudicadas por la pérdida de control que sufren como consecuencia del delito, por lo que necesitan recuperarlo transformándose en participantes del proceso restaurativo y trasladando, paulatinamente, parte del control formal o punitivo del Estado al control social informal de redes y contención social, teniendo como base la confianza en las personas y su posibilidad de resiliencia.

La reparación, al potenciar y promover la satisfacción de los intereses y necesidades de la víctima, posibilita la coincidencia de estos con el proceso penal, facilitando su comprensión y participación en él. Ello puede ser útil al sistema tradicional, ya que como se sabe las necesidades e intereses de la víctima no siempre se encuentran representados por el Ministerio Público, y el sistema en ocasiones impide a la víctima obtener la compensación que merece.

En cuanto a la víctima, Maier ${ }^{26}$ considera que la conciliación entre autor y víctima y la reparación son soluciones posibles para desplazar la coacción penal o para suavizarla, en ciertos delitos que a pesar de su gravedad generan costos adicionales de nivel privado para la víctima, si no son tratados de esta manera. Expresando que: "Por mucho tiempo la víctima pasó a ser el convidado de piedra del sistema penal. La función de reparación desapareció en este sistema y quedó solo como objeto de disputa entre intereses privados, el Derecho Penal no incluyó a la víctima ni a la reparación del daño entre sus fines, y el Derecho Procesal Penal ${ }^{27}$ solo le reservó al ofendido un papel secundario, el de informar para conocimiento de la verdad. Se habla por ello de una expropiación de los derechos del ofendido, al erigir al Estado como portador del monopolio legítimo de la fuerza y garante de las condiciones de vida" ${ }^{28}$.

${ }^{26}$ Maier, J., Derecho Procesal Penal argentino, Editorial Hammurabi, Buenos Aires, 1989, pp. 186-187.

${ }^{27}$ Ley N ${ }^{\circ}$ 19.696, Código Procesal Penal, 12 octubre 2000, Artículo 178: El denunciante no contraerá otra responsabilidad que la correspondiente a los delitos que hubiere cometido por medio de la denuncia o con ocasión de ella. Tampoco adquirirá el derecho a intervenir posteriormente en el procedimiento, sin perjuicio de las facultades que pudieren corresponderle en el caso de ser víctima del delito".

${ }^{28}$ Maier, J., Derecho Procesal Penal argentino, op. cit. pp. 245-247. 
Al respecto, Galaway ${ }^{29}$ afirma que numerosos estudios muestran que la víctima prefiere la reparación del infractor antes que la del Estado, porque la primera consigue la reorganización constructiva entre ofensor y víctima, obteniéndose objetivos metapenales con mayores beneficios que los proporcionados por el control punitivo estatal.

Por otra parte, para Larrauri ${ }^{30}$ la participación de la víctima en el proceso permite su incorporación en la evaluación de los hechos, siendo informada de sus derechos y razones por las cuales ocurrieron los hechos. A su vez, ella explica su angustia, sus necesidades y la forma de reparación que requiere, devolviéndosele su dignidad perdida, explicitándose que no es merecedora de la lesión y que tiene el derecho a ser respetada en su integridad. Lo que no significa que deba permitirse la sensación de impunidad ante la violación de la norma, sino que debe promoverse la actuación del Estado en la medida en que no quepa esperar de los directamente interesados una resolución equitativa del conflicto.

Eser $^{31}$ afirma que cuando se priva al autor y a la víctima de la posibilidad de resolución del conflicto, o se les otorga menor protagonismo en la reparación del daño y mayor importancia a la imposición de una pena, se traslada la capacidad resolutiva a una instancia superior, produciéndose la despersonalización del conflicto. De este modo, el delito se transforma en un ataque al Estado y la punición en un fin, en donde el autor del daño se ve a sí mismo como responsable únicamente frente al sistema, mientras la víctima se siente abandonada e instrumentalizada en interés del Estado ${ }^{32}$.

Por su parte, Eiras ${ }^{33}$ sostiene que para hacer una comparación entre la justicia retributiva y la justicia restaurativa es necesario entender que en el sistema tradicional la responsabilidad por las conductas es individual, a diferencia del modelo restaurativo, el que, sin dejar fuera esta responsabilidad, considera también las circunstancias, la historia, las interpretaciones, el entorno y los grupos de poder que influyen. Asimismo, los sistemas se diferencian en relación con la finalidad. El procedimiento retributivo tiene como objetivo probar delitos, establecer culpas y aplicar el castigo, dejando de manifiesto una orientación hacia el pasado, en función de la investigación de los hechos acontecidos. En cambio, para el sistema restaurativo los objetivos son la resolución del conflicto, el asumir responsabilidades y la reparación del daño causado. El que sin dejar de integrar el pasado y los daños causados, se sitúa en una perspectiva de futuro.

29 Galaway, B., "Victim participation in the penal corrective process", en Revista Victimology, An International Journal, Vol. 10, Estados Unidos, 1985, pp. 626 y ss.

${ }^{30}$ Larrauri, E., en Bustos, J. y Larrauri, E., Victimología: Presente y futuro. Hacia un Sistema Penal de Alternativas, Editorial PPU, Barcelona, España, 1993, pp. 91 y ss.

${ }^{31}$ Eser, A., Nuevos horizontes en la Ciencia Penal, Editorial Belgrano, Buenos Aires, 1999, pp. 26 y ss.

32 Eser, A., Nuevos horizontes en la Ciencia Penal. Op. cit., pp. 27 y ss.

${ }^{33}$ Eiras N., Ulf C., Mediación Penal, de la Práctica a la Teoría, $1^{a}$ edición, Editorial Histórica, Buenos Aires, Argentina, 2004, pp. 36 y ss. 


\section{LA MEDIACIÓN, Y LAS DIFERENCIAS DE GÉNERO}

La mediación supone un proceso colaborativo en que las partes por sí mismas sean capaces de llegar a la solución de un conflicto. Operando a base de principios rectores $^{34}$, enunciados también en la Ley de Tribunales de Familia como son los principios de igualdad, voluntariedad, confidencialidad, imparcialidad del mediador, el interés superior del niño y la consideración de opiniones de terceros. Es así que la mediación exige que sus participantes se encuentren en una condición de igualdad para resolver sus diferencias. Es precisamente este principio el que se ve cuestionado cuando se trata de incorporar la perspectiva de género a la mediación, ya que si se efectúa una mirada profunda a la realidad nacional, y particularmente en el seno de la familia chilena, es fácil constatar que las relaciones de las mujeres frente a los hombres han sido y son históricamente desiguales.

Los varones tradicionalmente han ocupado el espacio público o el ágora, el trabajo formal y la política; y las mujeres en general han permanecido en el ámbito de lo privado, siendo su espacio natural de desarrollo la maternidad, el cuidado de la casa, del progenitor y de los/as ascendientes y descendientes, en resumen, la familia y el hogar.

Esta división no solamente establece las condiciones sociales estandarizadas de cumplimiento del rol social según sexo, sino que además jerarquiza los estereotipos de "hombre" y de "mujer", tanto en lo colectivo como en lo individual. Esto se manifiesta en la estructura familiar a partir del eje padre/varón, que ocupa el vértice superior, quien ordena y supedita a los demás miembros del grupo familiar, principalmente a la mujer, asignándoles roles y funciones ${ }^{35}$.

A esta construcción social no ha estado ajeno el Derecho, que desde la visión del legislador (mayoritariamente masculino) regula las conductas de los hombres y mujeres, configurando una estructura jerárquica de la familia que ha contribuido a reproducir y reforzar la desigualdad de género en perjuicio de la mujer ${ }^{36}$.

Es así que el ámbito del Derecho Matrimonial y de Familia muestra un conjunto de normas discriminatorias en materia de regímenes patrimoniales del matrimonio, en cuanto a la jefatura de la sociedad conyugal, la administración de bienes propios, la asignación del cuidado personal de los hijos/as a las madres. Lagarde sostiene que las diferencias biológicas sobre las cuales se construyen las desigualdades en el Derecho se manifiestan en las responsabilidades, cargas y funciones al interior de la familia ${ }^{37}$.

${ }^{34}$ Suárez, M., Mediación y Conducción de Disputas, Comunicación y Técnicas, 5 a edición, Buenos Aires, Editorial Paidós, 2005, p. 50.

35 Olavarría, J., "Hombres, identidades y violencia de género", en Revista de la Academia, N 6, Santiago, 2001, p. 118.

${ }^{36}$ Veloso, P., "Igualdad y relaciones familiares", en Revista Jurídica de la Universidad de Palermo, Buenos Aires, SELA, año 2000, p. 235.

${ }^{37}$ Lagarde, M., Los cautiverios de las mujeres: madresposas, monjas, putas, presas y locas, $3^{\mathrm{a}}$ ed. D.F. México. Universidad Nacional Autónoma de México, Programa Universitario de Estudios de Género, 2003, p. 168. 
Por otro lado, históricamente se entiende que los conflictos familiares pertenecen prioritariamente al género femenino, como principal usuaria del sistema, sino también porque los operadores son en su mayoría mujeres, tanto a nivel de judicatura como de profesionales litigantes. Es por ello que desde el mundo del Derecho se ha sostenido que los conflictos familiares son "temas femeninos" y, por ende, privados, lo que explica que se consideren de segunda categoría en la cultura legal y judicial.

El Derecho opera principalmente hacia y entre contendores que pertenecen a los estratos socioeconómicos más necesitados, quienes mantienen y reproducen las concepciones clásicas del género femenino y masculino. Estas desigualdades sociales, económicas y culturales que no pueden ser resueltas por el sistema procesal no debieran incidir en el trato del tribunal y de la ley en la protección de los derechos ${ }^{38}$.

Desde otro punto de vista más inclusivo y garantista, la mediación puede dar cuenta de la tensión actual y mayoritaria de la vida moderna, causada por el progresivo protagonismo femenino en la vida laboral, política y social, que rompe las bases bajo las cuales se construyeron los prototipos tradicionales de marido, mujer, padre, madre, hijo e hija, que justificaban la inferioridad y discriminación hacia la mujer, relegándola a su rol "natural", de la mantención y cuidado al interior del hogar.

La mediación, al promover relaciones igualitarias entre las partes, permite que este mecanismo ofrezca una oportunidad de equilibrar poderes, ya que mediante el diálogo se fortalece un proceso de empoderamiento de los participantes, quienes asumen en el análisis y resolución del conflicto un rol protagónico que favorece la oportunidad de discutir los problemas bajo condiciones de respeto y reconocimiento mutuo.

Las reglas del proceso y la conducción del mediador con técnicas y herramientas comunicacionales permite redefinir los roles en la familia y enseñar a la pareja formas de relacionarse en que prevalece el respeto mutuo.

Lo antes expresado lleva a concluir que la práctica de la mediación, como mecanismo de autotutela jurisdiccional, constituye una importante herramienta para que a partir de la obtención de acuerdos se redefinan y establezcan nuevas identidades de género, produciéndose un cambio cultural significativo para los participantes, pero especialmente para sus hijos.

El mayor desequilibrio de género se expresa en la VIF, pues en torno a los roles que la cultura da a lo femenino y masculino se entrega a este último (al hombre), en razón de su superioridad, el poder de castigar emocional y físicamente a la mujer cuando ella no responde a los cánones sociales.

${ }^{38}$ Carocca, A., "Derechos humanos y Derecho Civil: perspectiva procesal", en Centro de Desarrollo Jurídico Judicial, Corporación de Promoción Universitaria, Serie Estudios, Santiago de Chile, 1997, p. 49. 


\section{LA MEDIACIÓN EN CONFLICTOS DE VIF}

Mucho se ha debatido sobre la factibilidad de la aplicación de la mediación en los conflictos de VIF, no encontrándose los estudiosos de este mecanismo contestes en cuanto a su pertinencia. No obstante las encontradas opiniones sobre la materia, nuestro ordenamiento jurídico contempla el uso de la mediación en este tipo de conflictos, pero solo en situaciones relativas a la organización familiar reguladas por la Ley de Tribunales de Familia ${ }^{39}$, y no propiamente en los temas relativos a la violencia. Prohibiendo su procedencia en los casos en que la VIF es constitutiva de delito y de conocimiento de los Tribunales con competencia en lo penal. Cabe entonces señalar que en asuntos en que tiene lugar la aplicación de la Ley $\mathrm{N}^{\circ} 20.066$, sobre violencia intrafamiliar, se encuentra la respuesta en el artículo $5^{\circ}$ de la misma ley ${ }^{40}$.

${ }^{39}$ Ley N 19.968 que crea los Juzgados de Familia, publicada en el Diario Oficial el 30 de agosto de 2004; en el artículo 106 señala los casos en los que procede la mediación, ya sea de manera previa o voluntaria, estableciendo algunas reglas especiales. A continuación, en relación con la violencia intrafamiliar señala? "En los asuntos a que dé lugar la aplicación de la Ley No 20.066, sobre Violencia Intrafamiliar, la mediación procederá en los términos y condiciones establecidos en los artículos 96 y 97 de esta ley”. En consecuencia, para determinar la procedencia de la mediación es necesario distinguir si la derivación se realiza o no dentro de un procedimiento judicial de violencia intrafamiliar, ya que para que sea posible la mediación en este contexto es necesario que el juez haya derivado a mediación, verificando el tribunal el cumplimiento de los requisitos establecidos en el artículo 96: "Suspensión condicional de la dictación de la sentencia. Si el denunciado o demandado reconoce ante el tribunal los hechos sobre los que versa la demanda o denuncia y existen antecedentes que permiten presumir fundadamente que no ejecutará actos similares en lo sucesivo, el juez podrá suspender condicionalmente la dictación de la sentencia, siempre y cuando se cumpla cualquiera de las siguientes condiciones:

a) Que se hayan establecido y aceptado por las partes obligaciones específicas y determinadas respecto de sus relaciones de familia y aquellas de carácter reparatorio a satisfacción de la víctima;

b) Que se haya adquirido por el demandado o denunciado, con el acuerdo de la víctima, el compromiso de observancia de una o más de las medidas cautelares previstas en esta ley por un lapso no inferior a seis meses ni superior a un año.

En todo caso, el tribunal, previo acuerdo de las partes y en conformidad a lo dispuesto en el inciso primero, podrá someter a mediación el conflicto para los efectos de la letra a). Aprobada el acta de mediación, el juez suspenderá condicionalmente la dictación de la sentencia. Para efectos de lo dispuesto en este artículo, el juez deberá ser asesorado por uno o más miembros del consejo técnico, asegurándose que las partes estén en capacidad para negociar libremente y en un plano de igualdad.

La resolución que apruebe la suspensión de la sentencia será inscrita en el registro especial que para estos procesos mantiene el Servicio de Registro Civil e Identificación, en los mismos términos que la sentencia.

La Ley $N^{\circ} 19.968$, en el inciso final del artículo 81, señala que el procedimiento por actos de violencia intrafamiliar se regirá por el procedimiento especial ante estos tribunales, el que, de acuerdo con lo señalado en el inciso primero del artículo 82 de la misma ley, podrá iniciarse por demanda o por denuncia, la que puede ser presentada por la víctima, sus ascendientes, sus descendientes o sus guardadores o personas que la tengan a su cuidado. La denuncia además podrá hacerse por cualquier persona que tenga conocimiento directo de los hechos que la motiven, a quien le será aplicable lo establecido en el artículo 178 del Código Procesal Penal.

${ }^{40}$ Ley $\mathrm{N}^{\mathrm{o}} 20.066$ de Violencia Intrafamiliar, publicada en el Diario Oficial con fecha 7 de octubre de 2005. Artículo 5: "Será constitutivo de violencia intrafamiliar todo maltrato que afecte la vida o la integridad física o psíquica de quien tenga o haya tenido la calidad de cónyuge del ofensor o una relación de convivencia con él; o sea, pariente por consanguinidad o por afinidad en toda la línea recta o en la colateral hasta el tercer grado inclusive, del ofensor o de su cónyuge o de su actual conviviente. 
En aquellos casos en que la violencia constituya delito no es procedente iniciar un proceso de mediación, ya que el artículo 19 de la Ley $\mathrm{N}^{\circ} 20.066$ ha prohibido en forma expresa la realización de acuerdos reparatorios en el tipo penal de maltrato habitual. Como en todo conflicto de carácter penal, es la Fiscalía quien tiene las herramientas y la responsabilidad de iniciar las diligencias tendientes a la protección de las víctimas de manera eficaz y oportuna, en concordancia con los artículos 15 y $16^{41}$.

Tradicionalmente los conceptos de orden público y autonomía de la voluntad se consideran antagónicos, atribuyéndole al Derecho de Familia una mayor restricción de la autonomía de la voluntad que a otras ramas del Derecho Civil, ya que la mayor parte de sus disposiciones son de carácter imperativo ${ }^{42}$. Sin perjuicio de ello, con el transcurso del tiempo se ha ido ampliando el ejercicio de la libertad en el ámbito familiar, otorgando a las partes derecho a celebrar acuerdos homologables, lo que no ocurre en materia penal, tratándose del mismo tipo de conflicto, separado por una ínfima línea divisoria, representando distintas caras de un mismo conflicto.

En este sentido, respecto de la capacidad autocompositiva de los participantes en una mediación, las partes deben ser capaces de asumir el conflicto, reflexionando sobre acciones personales para resolverlo, haciéndose cargo de su participación en él, lo que es condición necesaria, aunque no suficiente, para solucionarlo ${ }^{43}$.

La discusión doctrinaria sobre la pertinencia de la mediación se basa precisamente en las características que definen a este mecanismo. Es decir, la mediación como un proceso colaborativo, voluntario, confidencial, donde las partes trabajan sobre la base de equilibrios de poderes que les permite situarse en un plano de horizontalidad para resolver un conflicto, buscando la satisfacción de sus necesidades.

${ }^{41}$ El artículo 19 de la Ley No 20.066 dispone: Artículo 19.- Improcedencia de acuerdos reparatorios. En los procesos por delitos constitutivos de violencia intrafamiliar no tendrá aplicación el artículo 241 del Código Procesal Penal. En materia de medidas cautelares, el artículo 15 de la norma precitada señala "Medidas cautelares. En cualquier etapa de la investigación o del procedimiento sobre delitos constitutivos de violencia intrafamiliar, y aun antes de la formalización, el tribunal con competencia en lo penal podrá decretar las medidas cautelares que sean necesarias para proteger a la víctima de manera eficaz y oportuna, tales como las que establece el artículo 92 de la Ley $\mathrm{N}^{\circ} 19.968$ y las aludidas en el artículo $7^{\circ}$ de la Ley $\mathrm{N}^{\circ}$ 20.066". A su turno, el artículo 16 de este mismo cuerpo legal señala "Medidas accesorias. Las medidas accesorias que establece el artículo $9^{\circ}$ serán aplicadas por los tribunales con competencia en lo penal, cuando el delito constituya un acto de violencia intrafamiliar, sin perjuicio de las sanciones principales y accesorias que correspondan al delito de que se trate. El tribunal fijará prudencialmente el plazo de esas medidas, que no podrá ser inferior a seis meses ni superior a un año, atendidas las circunstancias que las justifiquen. Dichas medidas podrán ser prorrogadas, a petición de la víctima, si se mantienen los hechos que las justificaron. En el caso de la letra d) del artículo $9^{\circ}$, la duración de la medida será fijada, y podrá prorrogarse, tomando en consideración los antecedentes proporcionados por la institución respectiva".

${ }^{42}$ Canales, P., La mediación familiar, conceptos generales y legislación extranjera, Biblioteca del Congreso Nacional de Chile, Departamento de Estudios Extensión y Publicaciones. Serie Estudios, Año XIII, No 278 , Santiago de Chile, julio de 2003, pp. 6 y ss.

43 Brandoni, F., "Reflexiones sobre la mediación y sus límites". En La trama, Revista Interdisciplinaria de Mediación y Resolución de Conflictos, Buenos Aires, Argentina, Año 1996. Documento disponible en http:// www.revistalatrama.com.ar/contenidos/laslecturas/index.php. Última visita 25 de febrero de 2010. 
Desde un enfoque del conflicto penal en la línea de la Justicia Restaurativa, la mediación no se centra en determinar culpables ni imponer sanciones, sino que insta a los participantes a responsabilizarse de sus actos y asumir compromisos futuros mediante acuerdos posibles de reparación.

Tapia e Ilundain afirman que quienes se oponen al uso de la mediación en casos que involucren violencia familiar, este mecanismo puede no respetar los derechos y las protecciones que el sistema judicial le otorga a la víctima, lo que sería contraproducente con el movimiento que ha permitido sacar el tema del ámbito privado y ha logrado imponer la conciencia de que la violencia doméstica es un problema de carácter social y público $^{44}$. Por otra parte, refuerza esta posición la idea que postula que mediar en casos de este tipo implica intervenir en relaciones en las cuales existe un notable desequilibrio de poder, por lo que podría ser peligroso promover que la víctima se arriesgue a perturbar al victimario, especialmente cuando la situación de abuso no ha cesado, agravando la situación de riesgo o vulnerabilidad en que se encuentra la víctima.

Se ha sostenido que uno de los postulados básicos de la mediación plantea a las partes dialogar poniendo acento en el futuro, lo que podría significar que eventualmente se minimicen o relativicen los hechos violentos vividos entre las personas, argumentándose que se trata de una situación pasada, permitiendo que quien ejerció violencia no asuma adecuadamente su responsabilidad, no abordándose la necesidad de modificar drásticamente este comportamiento. Lo que podría ser efectivo si se considera que la mediación en familia no trabaja en función del concepto de culpa, lo que puede impedir el reconocimiento de la violencia, con efectos psicológicos negativos en la víctima.

Situación que se produce precisamente por una confusa división entre la mediación en familia y en materia penal, que tiene formas de intervención distintas, sobre un conflicto que integra ambos aspectos como es el VIF, que debe ser tratado integrando todas sus facetas familiares y penales y con aspectos propios de la Justicia Restaurativa, que no evita mirar al pasado y trata duramente la ofensa, persiguiendo que el ofensor reconozca su culpa, se arrepienta y repare. Sin embargo, como en nuestro país la procedencia a mediación está prohibida en VIF, tanto en materia familiar como penal, y regulada por ley su derivación por procedimiento especial en el área de familia, solo en aspectos anexos al conflicto y propias de la organización de la familia, posterior a la ofensa, donde el tratamiento del VIF como tal debe obviarse, invisibilizándosele, permitiendo solo su abordaje en el ámbito judicial.

En gran parte de los casos las posibilidades que el sistema de administración de justicia ofrece a este tipo de conflictos no otorga una salida lo suficientemente reparadora en atención a las necesidades de las partes. Esto debido a que el método del litigio judicial incorpora un sistema de ataque y defensa, e incluso de prueba, sobre aspectos muy íntimos de la familia, lo que trae como consecuencia una profundización del conflicto. En este sentido, el proceso de denuncia y tramitación judicial generalmente provocan una escalada en la violencia y prolonga el conflicto, generando angustia e insatisfacción

\footnotetext{
${ }^{44}$ Ilundain, M. y Tapia, G., “Mediación y Violencia Intrafamiliar”, op. cit., p. 12.
} 
a la víctima, quien se siente desamparada y no reconocida en sus derechos y dignidad por el sistema de administración de justicia, destruyéndose además de forma permanente la relación familiar. En tanto, con la mediación se pretende inscribir el conflicto en un marco de cooperación, con miras no a la disolución de la familia, sino a su reorganización, entregándole a las partes la posibilidad de regular sus relaciones futuras ${ }^{45}$.

Rifkin, que ha trabajado en el tema junto a Sara Cobb, sostiene que las víctimas son a veces sometidas al poder de los abogados en contra del victimario. Estas autoras entienden que trabajando desde la mediación con un procedimiento especial se puede ayudar a las víctimas a comunicarse de modo más seguro con el abusador y lograr poner fin a la violencia. También consideran que esta vía puede llegar a ser efectiva para intentar que los victimarios exploren la opción de un tratamiento ${ }^{46}$.

Aquellos que aceptan la mediación para algunos casos en que exista violencia están contestes en que no es posible hablar de reglas generales, ya que los casos de violencia difieren entre sí, y esto afecta la efectividad y los riesgos de la intervención.

Los programas que incluyen mediación en VIF habitualmente incorporan un diagnóstico previo de la situación, para evaluar si el caso es apto para ser trabajado en mediación e incorporan en la solución redes de intervención, integrales e interdisciplinarias. El procedimiento utilizado suele ser el denominado shuttled mediation, donde se trabaja en sesiones privadas con cada parte; esto evitaría la intimidación y la agresión en la relación víctima-victimario durante las sesiones (mediación puente).

Respecto de los acuerdos que se alcancen en una mediación por hechos de violencia, se prevé que tengan en cuenta determinadas características: que se incluya una exposición de los hechos violentos denunciados, como antecedente para ser utilizado si la violencia vuelve a ocurrir, que el acuerdo incluya una cláusula de no contacto, compensación económica de los gastos a que dieran lugar los hechos de violencia, que este acuerdo sea homologado por el juez y pueda tener valor de sentencia y seguimiento por el mediador del cumplimiento del acuerdo ${ }^{47}$.

Ello hace pensar que la mediación es aconsejable solo en los casos en que la violencia ya cesó; y en los casos en que esta no ha cesado, podría ser adecuado derivar a las partes a mediación solo una vez que el juez haya tomado las medidas cautelares para hacer cesar la violencia y siempre que el diagnóstico previo que se haga a la víctima establezca la posibilidad de esta de autodeterminarse y disponga de una red de apoyo integral que pueda actuar frente a un riesgo. Entendiendo que este mecanismo colaborativo puede aportar, junto a otras intervenciones, para que la pareja lleve adelante una redefinición de las reglas de relación que sostengan en forma autónoma.

En las relaciones violentas basadas en la complementariedad, el proceso y las herramientas de la mediación por sí solas no son instrumentos adecuados para generar

${ }^{45}$ Canales, P., La mediación familiar, conceptos generales y legislación extranjera. Ob. cit., pp. 6 y ss.

${ }^{46}$ Gianella, C. y Curi, S., "Mediación y violencia familiar en el contexto judicial”, en Revista La Ley, Gran Cuyo, año 7, N 3, Mendoza, junio 2002, pp. 305.

${ }^{47}$ Folberg, J. y Taylor, A., Mediación. Resolución de conflictos sin litigio, Editorial Limusa, México D.F., 1996 , p. 185. 
modificaciones, ya que la violencia forma parte de la identidad de sus actores. La utilización de la mediación en estos casos implica la necesidad de cambios previos que modifiquen las relaciones y que logren su autoimagen y una imagen del otro, que admitan la negociación previa colaboración de medidas cautelares de salud.

Además, en estos casos, cuando reiteradamente uno de los miembros es quien ejerce el poder y el otro quien lo sufre, es necesario indagar si los que la sufren tienen conciencia de ella y pueden comenzar a poner límites a las situaciones de abuso (haber cesado en la convivencia, solicitado la intervención de algún servicio profesional, policial, judicial, etc.) o si se encuentran en proceso de modificar la interacción ${ }^{48}$.

El escenario de la mediación es un recurso de esperanza para esas familias, especialmente cuando las personas no pueden hablar, operando como un modo de desafío al silencio, ya que al mostrar el operador interés y aceptación por lo que tiene para decir, convoca a hablar a aquel/lla que está silenciada.

El tratamiento de la VIF en el contexto judicial obliga a una parte a defenderse, negando la existencia del delito; mientras que la otra parte está buscando un contexto de protección, generalmente judicial, en que un tercero va a decidir por ella. La víctima se ve impedida de reconocer en sus declaraciones ante el tribunal el dolor y el daño que le causó la acción del ofensor, por las consecuencias que podría traer una sentencia severa, que aplique penas privativas de libertad al infractor, con quien existen vínculos de afecto, perjudicando a la familia, si es que es el ofensor quien la sustenta económicamente.

En materia penal, la posibilidad de aplicar mecanismos propios de la Justicia Restaurativa a la violencia doméstica y de género constituye una opción muy discuti$\mathrm{da}^{49}$, debido a que no son aplicables los elementos restaurativos, como la petición de disculpas, el perdón y la reparación a la realidad práctica de la violencia doméstica y de género. Existiendo inconsistencia frente a los principios feministas, que consideran un retroceso volver estos conflictos al ámbito privado, con lo difícil que ha sido lograr llevarlos al público, con aspectos de criminalización y judicialización.

Por otra parte, teniendo presente que el equilibrio de poderes es propio de los sistemas restaurativos, es difícil pensar que este exista en los casos de violencia doméstica o de pareja, en que una de las partes ejerce poder y control sobre otra, lo que hace imposible ocupar mecanismos colaborativos para tratar estos conflictos.

Asimismo respecto de la voluntariedad de la participación en los procesos restaurativos, tampoco se puede sostener que esté garantizada, ya que puede la víctima estar coaccionada por el agresor a participar frente a la posibilidad de este de evitar una sanción o que se le imponga una más baja por un acuerdo. Incluso la voluntad del agresor es dudosa, encontrándose ante la misma posibilidad de elección.

\footnotetext{
${ }^{48}$ Greco, B. y Vecchi, S., "La mediación como recurso de intervenciones democratizadoras en las relaciones de poder: Mediación y Violencia Familiar", en Revista de Derecho de Familia, Revista Interdisciplinaria de Doctrina y Jurisprudencia, No 24, Buenos Aires, Editorial LexisNexis, 2003, pp. 19-24.

49 Villacampa Estiarte, C., "La Justicia Restaurativa en los supuestos de la violencia doméstica y de género", en La Justicia Restaurativa: desarrollo y aplicaciones, Tamarit Sumalla, J., Editorial Comares S.I., Granada, 2012, pp. 99-111.
} 
También, respecto del ofensor se dice que no se respetan sus derechos de garantizarle un debido proceso cuando al no existir acuerdo se debe retornar al proceso penal habiéndose abierto el diálogo sobre los hechos ocurridos, sin perjuicio de operar en la mediación penal el principio de confidencialidad y el secreto profesional.

Otro aspecto propio de la Justicia Restaurativa es la petición de disculpas y el perdón, los que son poco confiables en un proceso de violencia que tiene como estrategia permanente e histórica el acudir a tales mecanismos para perpetuar su ciclo.

En esta misma línea, el elemento de participación de la comunidad propios de estos procesos restauradores son poco sostenibles en los casos de VIF, ya que la comunidad ha sostenido frente a ellos una actitud trivializadora, invisibilizándola, lo que no garantiza que su intervención ofrezca garantías de asumir seriamente el conflicto.

Finalmente, también se plantea que no puede la Justicia Restaurativa garantizar la seguridad y protección de la víctima, al carecer de herramientas para ello.

\section{LA VIF Y VIOLENCIA DE GÉNERO FRENTE A LA JUSTICIA PENAL LITIGIOSA}

En el 2005, con la Ley $\mathrm{N}^{\circ} 20.066$ de VIF se agrega una nueva respuesta a este conflicto de carácter penal creando nuevos delitos y penas, motivada especialmente por movimientos feministas y de derechos humanos. Postura que a partir de los años 80 y 90 se radicaliza con la influencia de la teoría de género, con aspectos propios del positivismo, produciéndose tensiones con la criminología crítica, que se opone a la demanda de mayor Derecho Penal ${ }^{50}$. La influencia de esta postura feminista es relevante en la promulgación de la Ley $\mathrm{N}^{\mathrm{o}}$ 20.480, en el 2010, denominada Ley de Femicidio, lo que según Jiménez es una expresión clara del Derecho Penal Simbólico, esto es, la convicción de que la extensión del Derecho Penal y el punitivismo puede impactar por sí solo en evitar la reincidencia en este tipo de delitos ${ }^{51}$. Dando por otra parte lugar a tipos penales abiertos que afectan el principio de legalidad y problemas de competencia del tribunal que otorga las medidas de protección. Produciendo adicionalmente con la agravación de las penas, e inclusión de las accesorias, afección al principio de proporcionalidad de la pena ${ }^{52}$.

Pese a que estudios recientes dan cuenta de que la intervención de la justicia penal como principal instrumento de contención parece no influir en el control de la VIF y tampoco en la protección frente a los principales factores de riesgo de las víctimas. Debido a la complejidad de su intervención, este conflicto produce problemas a nivel

${ }^{50}$ Jiménez Allendes, M.A.; Medina González, P., Violencia contra la pareja en la justicia penal, Mayores penas mayor violencia, Editorial Librotecnia, Santiago, 2011, pp. 662-664.

${ }^{51}$ Jiménez Allendes, M.A.; Medina González, P., Violencia contra la pareja en la justicia penal, Mayores penas mayor violencia, op. cit., pp. 19-20.

52 Jiménez Allendes, M.A., Medina González, P., Violencia contra la pareja en la justicia penal, Mayores penas mayor violencia, op. cit., pp. 669-670. 
de operadores, aumentando sus exigencias y sobrecarga de trabajo, lo que debilita su gestión y hace difícil la fiscalización de las medidas de protección. En cuanto a las víctimas, las respuestas que da la justicia penal son temporales y parciales, sin ofrecer una solución real al conflicto, debilitando su posición y en cuanto a los imputados aumenta la judicialización y las penas, sin lograr evitar su reincidencia ${ }^{53}$.

Por otra parte, en cuanto a los delitos que se denuncian son de baja lesividad, en contraste con aquellos graves hechos que se denuncian en forma mediática, como homicidios o lesiones graves que son los de menor ocurrencia, pero sin embargo determinan una respuesta homogénea y estandarizada para todos ellos, no ofreciéndose respuestas focalizadas y específicas. Lo que lleva a pensar que la intervención penal debiera focalizarse a los casos más graves, actuando como complemento de políticas sociales y de prevención en los más leves ${ }^{54}$.

Actualmente han aumentado de forma cuantiosa las denuncias de las mujeres sobre violencia de género y familiar, alcanzando a 136.410 en el 2010, con un aumento en cinco años de $43 \%$, siendo estas muy heterogéneas y difíciles de abordar. Encontrándonos con registros de los operadores muy poco específicos. Sin perjuicio de representar un importante avance las encuestas de victimización efectuadas el 2008 por el Ministerio del Interior, las que incluyen este tipo de delitos ${ }^{55}$.

Las tasas de las sentencias definitivas en esta materia según las cifras del Ministerio Público aumentan seis veces entre 2006 y 2008, llegando las condenas a 97\% en relación con las absolutorias que alcanzan $3 \%$. Correspondiendo sus penas principalmente a privativas de libertad efectiva, 24\%; con medidas alternativas de la Ley $\mathrm{N}^{\circ} 18.216$, $55 \%$, y $20 \%$ con multas 56 .

\section{Entre los ARgumentos a FAVOr de la APLiCACión de LA Justicia Restaurativa}

En los casos de violencia doméstica y de género, se afirma que las víctimas al acudir a denunciar el hecho a la policía buscan conseguir protección inmediata, que su pareja o expareja sea detenida y expulsada del hogar común, o bien que sea advertido de cesar su actitud violenta, esperando apoyo y protección. Sin embargo la diferencia de lo que la víctima espera y lo que obtiene cuando entran en contacto con el sistema de justicia penal le produce decepción, debido a que este tipo de juicios termina reiteradamente

53 Jiménez Allendes, M.A.; Medina González, P., Violencia contra la pareja en la justicia penal, Mayores penas mayor violencia, Editorial Librotecnia, Santiago, 2011, pp. 19-20.

${ }^{54}$ Jiménez Allendes, M.A.; Medina González, P., Violencia contra la pareja en la justicia penal, Mayores penas mayor violencia, Editorial Librotecnia, Santiago, 2011, p. 20.

${ }^{55}$ Jiménez Allendes, M.A.; Medina González, P., Violencia contra la pareja en la justicia penal, Mayores penas mayor violencia, op. cit., pp. 675-677.

${ }^{56}$ Jiménez Allendes, M.A.; Medina González, P., Violencia contra la pareja en la justicia penal, Mayores penas mayor violencia, op. cit., p. 681. 
con una sensación para la víctima y comunidad de denegación de justicia, porque estos procesos terminan con una absolución, una pena menor o con una suspensión condicional del procedimiento. Resultado que se produce al no poderse probar el delito o su intensidad, al verse obligada la víctima a ocultar los hechos o a desvalorar la ofensa y los daños sufridos por la violencia, ante la posibilidad de hacer pública una situación que la avergüenza o frente a la imposición de un castigo a un miembro de la familia con el que existen profundos lazos de afecto. Es así como la víctima se ve afectada en su dignidad y su posterior credibilidad frente al sistema público, dejándola más vulnerable frente a ataques futuros. Además de sufrir una revictimización por el sistema público.

Por otra parte, si esta tiene delante de sí solo al infractor y no recibe del autor un real reconocimiento y solicitud de perdón, producto de un profundo proceso de comprensión del daño, se fomenta en ella el rencor, el odio y el temor difuso, sin poder reestructurar su necesidad de reconocerse como víctima con derecho a ser reparada.

$Y$ por su parte el ofensor, para su defensa, se ve compelido a desconocer el daño causado a la víctima, lo que le impide reconocer el delito en su total magnitud. De esta manera, la situación antes descrita aumenta la posibilidad de reincidencia del infractor, al verse respaldado por la justicia, en impunidad o con una pena menor y sin reconocimiento personal de la gravedad del daño causado.

También es necesario agregar que el sistema tradicional no permite a las personas dejar de ser sujetos pasivos de un tratamiento institucional y burocrático, para pasar a ser sujetos activos en la definición de los conflictos de que forman parte y en la construcción de los instrumentos para resolverlos, según sus propias necesidades.

Ahora, si en lugar de un proceso penal con la amenaza inminente de una pena privativa de libertad para el autor se trabaja en estos casos con un proceso colaborativo, como el de mediación penal, con el aporte de un equipo interdisciplinario, permitiría a las víctimas y a los ofensores reconocerse como tal, siendo duros con el daño y el delito y blandos con las personas. Este tratamiento permitiría además una reparación a la víctima que efectivamente le sea significativa y al imputado encontrar una forma de reparar a esta con la ayuda de la comunidad. Sin perjuicio de las medidas cautelares y de protección que debe ofrecer el sistema jurisdiccional a la víctima.

De un modo general, la reparación, junto con ser proporcional al daño, puede ser de tipo material, moral y simbólica, y debe ser suficiente de acuerdo con las necesidades de la víctima, quien debe participar en su determinación, cuantificación y señalamiento.

Entre las diversas formas de reparación puede señalarse, a modo ejemplar, la restitución individual, que consiste en el pago por parte del infractor de una suma de dinero para compensar a la víctima por las pérdidas causadas por el delito, u otra forma de restitución material, como la reparación material de daños causados. También está la posibilidad de realizar servicios a la comunidad o reparación colectiva. Este servicio puede realizarse a título personal o en representación de la víctima. Otra forma de contribución es la reparación simbólica, que consiste en la prestación realizada a favor de las víctimas o de la comunidad, que tienda a asegurar la preservación de la memoria histórica, la no 
repetición de los hechos, la aceptación pública de estos, el perdón público y la entrega de garantías de no repetición de las conductas ilícitas.

En la reparación propuesta por el sistema restaurativo "encontramos también uno de los fines tradicionales del Derecho Penal, el fin reeducativo y rehabilitativo de prevención especial. Primero, porque la posibilidad de reparación constituye un estímulo para la denuncia de la víctima, y segundo, porque al no ser fijada por el juez la reparación, da cabida a la dimensión humana de la víctima, lo que propicia un efecto educativo al autor que se responsabiliza, previa depuración de las inferencias autoexculpatorias, que le permiten recordar el hecho delictivo en contraposición a la pena, la que simboliza un medio de saldar una abstracta deuda con el Estado" 57.

La reparación no puede ser considerada como una pena, por carecer de un potencial de amenaza, y por lo tanto, ser inútil como prevención general negativa. Sin embargo, Roxin $^{58}$, compartiendo que no es la reparación una pena, le atribuye un fin de prevención general positiva, como una tercera vía entre la falta de reacción oficial y la reacción punitiva, lográndose el efecto preventivo cuando se obtiene la resolución pacífica de la situación perturbada.

Las experiencias sobre justicia restaurativa y en especial de mediación penal en otros países, muestran que en estos casos si en lugar de un proceso punitivo se aplica un proceso colaborativo, con los resguardos previos necesarios, como la adopción de medidas cautelares, el infractor comprenderá que más allá de haber violado la ley, ha realizado una acción negativa desde el punto de vista humano frente a un otro al cual logra ver como un legítimo otro ${ }^{59}$, porque quien ha sido ofendido no es un abstracto como lo es la ley, sino una persona real. La dimensión de la relación humana, primero ausente en la percepción del culpable, se pone en total evidencia en este proceso.

Asimismo, siguiendo con los beneficios de los procesos restaurativos en estas materias, podemos señalar que otro valor agregado es la inmediatez resolutiva del modelo, que no se vincula a una solución rápida y maquinal y tardía, sino que permite que el conflicto se aborde en su fase crítica, cuando es más viable reconducir las emociones y orientarse a una meta constructiva.

Finalmente, los costos son menores que un proceso litigioso, ya que evita gastos materiales, morales y psicológicos, al suscitar menos rencor y hostilidad en las partes, porque se mantiene el control emocional al equilibrar el poder en los involucrados. De este modo se promueve que la víctima se sienta menos víctima, y no se estigmatice al infractor, destinando los recursos judiciales focalizadamente.

${ }^{57}$ Muñoz Ramírez, E., "La Reincidencia en el Derecho Penal”, en Revista de Derecho Universidad Central de Chile, 2007, l, t., pp. 185-203.

58 Roxin, C., "La reparación en el sistema jurídico penal de sanciones", Cuadernos del Consejo General del Poder Judicial, $\mathrm{N}^{\circ} 8$, Madrid, España, 1991, pp. 19 y ss.

59 Maturana, H., Ponencia en Foro Iberoamericano de Justicia Restaurativa y Colaborativa, Ministerio de Justicia, Santiago, Chile, 2006. 


\section{Experiencias de Justicia Restaurativa APLiCAdAS A CONFLICTOS DE VIF}

Según afirma Villacampa ${ }^{60}$, las evaluaciones sobre la intervención de la Justicia Restaurativa en este complejo tema se han centrado en analizar el grado de satisfacción de la víctima con el proceso, no así con los resultados obtenidos, los que arrojan en general un resultado positivo. Mayoritariamente, las víctimas se muestran satisfechas por el grado de participación que han tenido en el proceso, más que con la reparación financiera o material recibida. Así lo confirma un análisis de treinta y cinco programas de Justicia Restaurativa efectuado el 2001, el que además incluye al ofensor en esta satisfacción por su participación en el proceso ${ }^{61}$.

En el análisis de los resultados de evaluaciones de programas sobre el tratamiento de conflictos mediante mecanismos de Justicia Restaurativa efectuados por Sherman y Strang ${ }^{62}$, se concluye que estos reducen la reincidencia en caso de delitos violentos como los de VIF y de pareja, lo que no se observó en los delitos no violentos, como los patrimoniales. A semejante conclusión se llegó en el estudio publicado en el 2008, en relación con tres programas de Justicia Restaurativa: el Connect, el programa Justice Research Consortium y el Remedi, desarrollados en Gran Bretaña, en el sentido de que el paso por sistemas restaurativos reducía sustancialmente el número de condenas en un período de dos años posteriores de seguimiento ${ }^{63}$. Razón por la que se puede sostener que si bien hay poca evidencia empírica de que la Justicia Restaurativa reduce efectivamente la VIF, hay menos antecedentes aún para sostener que la justicia tradicional lo haya hecho.

\section{Conclusiones}

A nivel nacional, la intervención litigiosa aparece en nuestra legislación como el único mecanismo de solución de este complejo tipo de conflictos, lo que como hemos visto es insuficiente para otorgar una respuesta adecuada a la dignidad y necesidades de las personas involucradas. Al respecto debe tenerse en cuenta la imposibilidad jurídica que existe de otorgar solución a un conflicto de violencia intrafamiliar por la vía colaborativa, tanto en materias sometidas a la competencia de los Tribunales de Familia

${ }^{60}$ Villacampa Estiarte, C., "La Justicia Restaurativa en los supuestos de la violencia doméstica y de género", en La Justicia Restaurativa: desarrollo y aplicaciones, Tamarit Sumalla, J., Editorial Comares S.I., Granada, 2012, pp. 99-111.

${ }^{61}$ Latimer, Dowden, Muise, The effectivenes of restorative justice practices: a meta-analysis, Canadian Department of Justice, Ottawa, 2001, The Prison Journal, 2005 v 85, pp. 127-144.

${ }^{62}$ Sherman, L. W. y Strang, H, Woods, d. j., Recidivism patterns in the camberra Reintegrative Shaming Experiments, 2000, p. 64 en http://www.aic.gov.au/criminal_justice_system/rjustice/rice/-I media/aic/rjustice/ rice/ricidivism/report.pdf.

${ }^{63}$ Shapland, Atkinson, A., Atkinson, H., Dignan, Edwards, Hibbert, Howes, John-Stone, Robinson, Sorsby, Does Restorative justice affect reconviction?, The fourth report from the evaluation of three schemes, Ministry of justice Ressearch Series, june, 2008, pp. 66-67. 
como en materia penal. Sin embargo, cabe destacar que el legislador ha establecido que bajo ciertas y específicas condiciones puede desarrollarse un proceso de mediación familiar que no se centre en la violencia, sino en establecer y aceptar por los participantes obligaciones específicas y determinadas respecto de sus relaciones de familia y que sean reparatorias para la víctima, lo que no es suficiente para tratar el conflicto real en materia de VIF, ya que lo invisibiliza.

Este artículo no tiene como propósito exhibir a la mediación y especialmente la mediación penal como un mecanismo infalible y aplicable en forma exclusiva a todos los conflictos que pueda vivenciar un grupo familiar, sino como un mecanismo que amplía sus posibilidades de solución, que requiere que su aplicación sea discrecional, ciñéndose no solo a las normas legales, sino psicosociales, y por qué no decirlo, éticas, que regulan el proceso.

En función de lo anterior, cabe señalar que la técnica legislativa utilizada para distinguir entre las situaciones de violencia intrafamiliar que constituyen delito y las que no lo son, son vagas e imprecisas, y no consideran adecuadamente la realidad en la que emerge este tipo de conflictividad, que no distingue entre materias familiares y penales. A este respecto los especialistas sostienen que una situación de violencia intrafamiliar es reconocida por las víctimas luego de cinco a siete años de existencia. Desde esta perspectiva, ningún caso que llega al sistema jurisdiccional podría estimarse como una situación no constitutiva de delito, ya que a la luz del delito de maltrato habitual, ${ }^{64}$ todas estas situaciones se enmarcarían en el citado tipo penal.

De cualquier modo, una adecuada intervención en estos casos requiere de mediadores con una formación especializada, particularmente en materias de género, familia y de orden jurídico, que en lo posible trabajen en forma interdisciplinaria con profesionales de la psicología. Situación por la que debe velar el Ministerio de Justicia, mediante la supervisión y control del Registro de Mediadores, ampliándolo a temas de mediación penal y especialmente en VIF.

Por otra parte, desde el órgano jurisdiccional se debe proporcionar a los mediadores y usuarios una red de contención institucional adecuada, que contenga instancias de tratamiento y reparación. De esta manera, el ideal en este tipo de intervenciones sería contar con una red que dé un enfoque integral al conflicto, aportando desde la interdisciplinariedad, salud mental, mecanismos colaborativos de solución de los conflictos y medidas cautelares que ofrezcan protección efectiva ante un caso de riesgo. Asimismo, los centros de mediación que intervienen en estas materias deben contar con un protocolo adecuado de parámetros de evaluación del riesgo para las partes, que trate tanto

${ }^{64}$ Ley $\mathrm{N}^{\mathrm{o}}$ 20.066, sobre Violencia Intrafamiliar, publicada en el Diario Oficial el 7 de octubre de 2005. Artículo 14. "Delito de maltrato habitual. El ejercicio habitual de violencia física o psíquica respecto de alguna de las personas referidas en el artículo $5^{\circ}$ de esta ley se sancionará con la pena de presidio menor en su grado mínimo, salvo que el hecho sea constitutivo de un delito de mayor gravedad, caso en el cual se aplicará solo la pena asignada por la ley a este. Para apreciar la habitualidad, se atenderá al número de actos ejecutados, así como a la proximidad temporal de los mismos, con independencia de que dicha violencia se haya ejercido sobre la misma o diferente víctima. Para estos efectos, no se considerarán los hechos anteriores respecto de los cuales haya recaído sentencia penal absolutoria o condenatoria. 
los aspectos de vulnerabilidad de la víctima, evitando una nueva victimización, como los índices de peligrosidad del ofensor.

El campo de acción de los mecanismos colaborativos como el de la mediación en violencia debiera definirse no a partir del delito, sino a partir de la vulnerabilidad de la víctima y del reconocimiento e intención de reparar del infractor, medidas por instrumentos técnicos psicosociales que permitan valorar adecuadamente aspectos como la voluntad real de cambio, conciencia de daño causado, habilidades en el manejo y control de emociones.

Respecto del proceso de mediación, se puede afirmar que tiene como propósito recuperar el respeto entre los integrantes de la familia y recrear los recursos familiares, centrados en la distribución equilibrada de poder y roles. El cambio cultural que implica la mediación incorpora modelos de género y autoridad, con necesidad de un cambio en los cánones de convivencia que no son fáciles, ni rápidos de transformar, y que requieren lograrse con un proceso que incorpore el análisis de las relaciones familiares mediante un procedimiento flexible, que integre la opinión de los miembros de la pareja, como iguales y de los hijos como piedra angular.

La familia que vive violencia y se incorpora a un proceso de mediación con éxito logra acuerdos en temas de reorganización familiar, transitando del caos y la violencia a un espacio más armónico, en que se toman decisiones que puede poner freno en forma transitoria a la violencia, mientras se encuentran formas más definitivas de trabajar con esta, y en otros casos permite instalar en sus miembros una nueva forma de funcionar frente a conflictos futuros.

Sin embargo, de existir un juicio en que se consignen los hechos en su real dimensión de gravedad, la sanción debiera tener un sentido no solo de castigo o represalia impuesta por el Estado, sino de relación directa con la lesión a un bien jurídico que el conjunto social ha estimado relevante proteger. Esa sanción es "aplicar reversa" a una acción que la sociedad no quería, pero centrándose en la reparación de la víctima, previniendo nuevas agresiones, sin llegar al extremo de victimizar al agresor. Este tipo de intervención colaborativa provoca a veces la resistencia de los operadores de justicia, por el traspaso de poder que esto implica a manos de los afectados, debido a que en el sistema retributivo el Estado expropia el conflicto a las partes, asignándole a la pena un sentido de prevención y rehabilitación. Por años se ha demostrado que la pena no es efectiva en ninguno de los sentidos antes citados, entre otras razones por las condiciones carcelarias de nuestro país; a diferencia del sistema colaborativo, el que fortalece el protagonismo de las partes y comunidad en la búsqueda de soluciones, dándoles el control sobre el proceso y trasladando el control formal al informal de la comunidad, el que permite desarrollar habilidades de empoderamiento y resiliencia en las víctimas y ofensores.

Es especialmente en este tipo de casos en que existen vínculos de familia donde opera con mayor eficacia una solución colaborativa, porque como en las comunidades originarias, los vínculos entre las partes van a permanecer, sobre todo cuando existen hijos comunes, lo que hace pensar que no es un acierto de nuestra legislación el excluir los acuerdos reparatorios como salida alternativa en materia de VIF. Es así como nuestra actual legislación nos obliga en la mayoría de los casos a resolver este delicado 
conflicto por medio de un proceso litigioso, en el que las partes deben defenderse como contrincantes y expresar lo más negativo del otro, rompiendo en forma definitiva los lazos de confianza y afecto en su familia. Y dejando en ellos la impresión amarga de que no se hizo justicia, no permitiendo al ofensor se enfrente a lo dañino de su acción y a la víctima reconocer su dolor.

Por último, el uso de las respuestas represivas en la regulación de los conflictos entre las personas que están en contacto permanente como la familia sirven para satisfacer temporalmente la demanda social, pero no puede constituir una respuesta adecuada a la complejidad de los conflictos en cuestión.

Es así como para optar por este desafío de ofrecer soluciones colaborativas, para los conflictos de VIF o pareja, se requiere de una sociedad equilibrada y madura, que no prejuzga ni toma partido por uno u otro, sino que desarrolla conductas destinadas a abrir y comprender dos realidades individuales complejas, transmitiendo adecuados patrones culturales de género.

\section{BiBLIOGRAFÍA}

Aguilar, Pager. "Estudio exploratorio sobre tendencias del marco legal contra la violencia intrafamiliar en América Latina", Contribuciones a las Ciencias Sociales, consultado en www. eumed.net/rev/cccss/07/daa6.htm.

Anitua, Gabriel Ignacio, Historia de los pensamientos criminológicos, Editores del Puerto SRL, 2010.

BARUsh, Bush y Folger, J.P., "La promesa de la mediación”. Editorial Granica, Barcelona. 1996.

BAtes, Luis. "Discurso de inauguración en Congreso Iberoamericano de Buenas Prácticas en Acceso a la Justicia". Santiago de Chile, 2006.

Baratta, Alessandro, "Notas para una teoría de la liberación”, en Revista Poder y Control, Editorial PPU. $\mathrm{N}^{\circ}$ 1, Barcelona, 1987. Criminología crítica y crítica al Derecho Penal, Editorial Siglo Veintiuno, Argentina, 2002.

Bergalli, Roberto, Sistema penal y problema social, Editorial Tirant lo Blanch, Valencia, 2003.

Bernardo, Ema; Greco, Silvana y Vecchi, Silvia, "La mediación como recurso de intervenciones democratizadoras en las relaciones de poder: Mediación y Violencia Familiar”, en Revista de Derecho de Familia, Revista Interdisciplinaria de Doctrina y Jurisprudencia, $\mathrm{N}^{\circ} 24$, Editorial LexisNexis, Argentina. 2003.

Binder, Alberto, Análisis Político Criminal, Editorial Astrea, Buenos Aires, 2011.

Brandoni, Florencia. "Reflexiones sobre la mediación y sus límites", en Revista La Trama, Revista Interdisciplinaria de Mediación y Resolución de Conflictos. Buenos Aires, 1996. Documento disponible en http://www.revistalatrama.com.ar/contenidos/laslecturas/index.php.

Bustos Ramírez, Juan; Hormazábal Malarée, Hernán; Nuevo sistema de Derecho Penal, Ed. Trotta, Madrid, 2004.

Canales, Patricia "La mediación familiar, conceptos generales y legislación extranjera". Serie Estudios, Año XIII, No 278. Biblioteca del Congreso Nacional de Chile, Departamento de Estudios, Extensión y Publicaciones. Santiago, 2003.

Carocca, Álex, "Derechos humanos y Derecho Civil: perspectiva procesal en Centro de Desarrollo Jurídico Judicial”. Corporación de Promoción Universitaria, Serie Estudios. Santiago de Chile. 1996. 
Castillo, Ana. Mediación Familiar y Género. Monografía de Magister en Derecho, Cultura Constitucional y Derechos Codificados. U. Central de Chile. Santiago de Chile, 2010.

Dorado Montero, Pedro, Valor social de leyes y autoridades, Barcelona, p. 198.

Folberg, J. y Taylor, A. Mediación. Resolución de conflictos sin litigio. Editorial Limusa, México DF. 2003.

FundACIÓN LibRa y FUNDACIÓN InTERNAS, "Manual de Entrenamiento en Mediación Familiar" Argentina. 1996.

GalaWAy, Burt, "Victim participation in the penal corrective process", en Revista Victimology, An International Journal, Vol. 10, Estados Unidos, 1985.

García-Pablos de Molina, Antonio, Manual de Criminología. Introducción y teorías de la criminalidad, Editorial Espasa, Madrid, 1988.

Gianella, Carolina y CuRI, Sara: "Mediación y violencia familiar en el contexto judicial", en Revista La Ley. Gran Cuyo, Año 7, N 3, Argentina. 2002.

Ilundain, Mirta y Tapia, Graciela. "Mediación y Violencia Intrafamiliar". En Revista La Trama, Revista Interdisciplinaria de Mediación y Resolución de Conflictos. Buenos Aires, 2001. Documento disponible ennhttp://www.colegiodemediadores.cl/documentos/doc_009_080613040653.PDF

Jiménez Allendes, M. Angélica; Medina González, Paula, Violencia contra la pareja en la justicia penal, Mayores penas mayor violencia, Editorial Librotecnia, Santiago, 2011.

LAGARDE Y DE LOS Ríos, Marcela, Los cautiverios de las mujeres: madresposas, monjas, putas, presas y locas. Universidad Nacional Autónoma de México, Programa Universitario de Estudios de Género. $3^{a}$ edición. D.F. México. 2003.

Latimer, Dowden, Muise, The effectivenes of restorative justice practices: a meta-analysis, Canadian Department of justice, Ottawa, 2001, The Prison Journal, 2005 v 85, pp. 127-144.

Molina, Natasha. "Los estudios de Género, Trayectoria y Aportes a la comprensión de la realidad social", en Revista de la Academia. N 6, Santiago, 2002.

Morris, Children and Family Violence Restorative Messages from New Zealand, en STRANG Y BRAITHWAITE, Restorative justice and Family Violence, Cambridge University Press, Cambridge 2012.

MuÑoz Ramírez, Eduardo, "La Reincidencia en el Derecho Penal”, La revista de Derecho, Universidad Central de Chile, 2007.

Olavarría, José. "Hombres, identidades y violencia de género", en Revista de la Academia, N 6 Santiago de Chile. 2001.

PEÑA, Carlos. "Los sistemas alternos de resolución de conflictos como alternativa de política pública en el sector judicial". En: Revista de Estudios Sociales de la Corporación de Promoción Universitaria (CPU), Nº 88, Año 1996.

Perrone, Reinaldo y Nannini, Martine, Violencia y abusos sexuales en la familia. Un abordaje sistémico y comunicacional. Buenos Aires, Editorial Paidós, 1997.

Roxin, Claus, "La reparación en el sistema jurídico penal de sanciones", Cuadernos del Consejo General del Poder Judicial, Nº 8, Madrid, España, 1991.

Shapland, Atkinson, A., Atkinson, H., Dignan, Edwards, Hibbert, Howes, John-Stone, RobInSON, SorsBy, Does Restorative justice affect reconviction?, The fourth report from the evaluation of three schemes, Ministry of Justice Ressearch Series, june, 2008.

Sherman, L. W. y Strang, H., Woods, D. J., Recidivism patterns in the camberra Reintegrative Shaming Experiments, 2000, en http://www.aic.gov.au/criminal_justice_system/rjustice/rice/-I media/aic/rjustice/rice/ricidivism/report.pdf.

SuÁrez, Marinés, Mediación y Conducción de Disputas, Comunicación y Técnicas. $5^{\text {a }}$ edición de Editorial Paidós, Buenos Aires, 2005.

Universidad de Concepción. Estudio "Calidad del Servicio de Mediación Licitado por el Ministerio de Justicia”, Ministerio de Justicia. Santiago de Chile, 2006. En: http://www. mediacionchile.cl/MinJusPubl/Sitio/pub_estadisticas.aspx. 
Unidad de Mediación, División Judicial, Ministerio de Justicia. Estadísticas del sistema nacional de mediación licitada en http://www.mediacionchile.cl/MinJusPubl/Sitio/index.aspx\#.

VArgas, Macarena. "Mediación Obligatoria. Algunas razones para justificar su incorporación”, en Revista de Derecho, V. XXI, N² Valdivia. 2008.

Veloso, Paulina. "Igualdad y relaciones familiares", en Revista Jurídica de la Universidad Palermo, Editorial SELA, Buenos Aires. 1999.

Villacampa Estiarte, Carolina, "La Justicia Restaurativa en los supuestos de la violencia doméstica y de género", en La Justicia Restaurativa desarrollo y aplicaciones, TAMARIt SuMALLA, Josep, Editorial Comares S.I., Granada, 2012.

Zaffaroni, Eugenio Raúl, Manual de Derecho Penal, Parte General. Criminología, Aproximación desde un margen, Editorial Temis S.A. Bogotá, 2003. 
